\title{
PERBANDINGAN METODE WEIGHTED PRODUCT (WP) DAN SIMPLE ADDITIVE WEIGHTING (SAW) PENILAIAN KINERJA GURU PADA MADRASAH IBTIDAIYAH NEGERI 3 JAKARTA
}

\author{
Joko Riyanto \\ Fakultas Teknik, Universitas Pamulang \\ e-mail: dosen00637@unpam.ac.id
}

\begin{abstract}
ABSTRAK
Salah satu upaya untuk meningkatkan kualitas lulusan lembaga pendidikan adalah dengan cara meningkatkan kualitas kinerja guru dalam proses mengajar. Maka dari itu dibutuhkan penilaian kinerja guru di sekolah agar meningkatkan kualitas lulusan suatu sekolah. Maslah -masalah dalam penilaian kinerja guru sering bermunculan antara lain Tak jarang guru hanya menampakkan kinerja baiknya hanya pada saat dikunjungi, kepala sekolah menilai kinerja guru secara subjektif, kepala sekolah mengevaluasi kinerja guru hanya dari satu kriteria saja, sehingga penilaian tidak objektif. Sehingga perlu adanya sistem pendukung keputusan untuk membantu menilai kinerja guru. Proses pembuatan sistem pendukung keputusan pada sistem penilaian kinerja guru ini menggunakan metode Weighted Product dan Simple Additive Weighting. Metode Weighted Product dan Simple Additive Weighting Dipilih Karena Mampu menyeleksi alternatif terbaik dan terburuk dari sejumlah alternatif, dalam hal ini alternatif yang dimaksud adalah kinerja guru sebagai bahan evaluasi kepala sekolah, untuk meningkatkan kualitas lulusan sekolah, berdasarkan kriteriakriteria yang telah di tentukan. Penelitian dilakukan dengan mencari nilai bobot untuk setiap atribut dengan cara memberikan siswa kuisoner, kemudian dilakukan proses perengkingan yang akan menentukan alternatif yang optimal, yaitu guru dengan kinerja terbaik dan guru dengan kinerja kurang baik. Berdasarkan pengujian yang dilakukan sistem yang dibuat mampu memberikan hasil yang baik sesuai dengan perhitungan yang digunakan, agar dalam penilaian kinerja guru lebih objektif, dan juga sistem dapat mengurangi kesalahan dalam menilai kinerja guru.
\end{abstract}

Kata Kunci: Sistem Pendukung Keputusan, Weighted Product, Simple Additive Weighting, penilaian kinerja guru

\section{PENDAHULUAN \\ Latar Belakang}

MIN 3 Jakarta merupakan salah satu sekolah yang menerapkan penilaian kinerja guru , jumlah guru yang berada di MIN 3 Jakarta 36 guru. penilaian kinerja guru dilakukan oleh kepala sekolah, penilaian kinerja ini dilakukan dengan kunjungan dan absensi. penialian kinerja guru melalui kunjungan yaitu, kepala sekolah mengunjungi guru pada saat jam sekolah untuk mengetahui kinerja guru dikelas secara langsung, kriteria yang digunkan dalam menilai diantaranya, penguasaan materi, mengajar sesuai kurikulum yang berlaku, penggunaan bahasa lisan dan tulisan yang baku, metode mengajar diantaranya mengajar menggunakan buku referensi, membagi kelompok untuk belajar siswa, menggunakan media (alat) untuk menerangkan kepada siswa, akan tetapi proses penilialan kurang objektif, karena bobot nilai kriteria tersebut sama tidak berbeda antar kriteria. jadi dalam proses perangkingannya kurang akurat.

Sedangkan penilaian kinerja yang menggunakan absensi proses perhitungannya menggunakan Microsoft Exel tanpa query oracle, contohnya admin menginput data absen dari document absen yang berupa kertas absensi. kertas absensi ditanda tangani setiap guru masuk.

Proses perhitungan yang menggunakan Microsoft Exel tanpa query oracle membutuhkan waktu yang relatif lama karena di Exel tanpa query oracle tidak memiliki database. oleh karena itu dibutuhkan suatu sistem yang dapat mempercepat proses perhitungan penilaian kinerja guru. untuk mendukung sistem penialain kinerja guru yang cepat dan akurat dibutuhkan suatu metode agar hasil yang di dapat sesuai yang diharapkan.

Metode yang digunakan untuk SISTEM PENUNJANG KEPUTUSAN PENILAIAN KINERJA GURU ini menggunakan metode Weighted Product (WP) dan Simple Additive 
Weighting (SAW), dua metode dipilih agar kepala sekolah diharapkan bisa mendapatkan dua alternatif pengolahan data untuk menunjang keputusan dalam penilain kinerja guru terbaik. kedua metode ini dipilih untuk membandingkan metode apa yang paling baik dalam proses perhitungan. dan karena hasil perhitungan kedua metode ini tidak terlalu jauh dan lebih efisien karena waktu yang dibutuhkan dalam perhitungan lebih singkat.

\section{Identifikasi Masalah}

Berdasarkan latar belakang tersebut didapat beberapa permasalahan diantaranya adalah:

a. Dalam proses perhitungan penilaian kinerja guru yang menggunakan Microsoft exel tanpa query oracle membutuhkan waktu yang lama karena tidak mempunyai database.

b. Dalam proses perangkingan kinerja guru kurang akurat karena bobot nilai kriteria sama.

\section{METODE PENELITIAN Analisa Sistem}

Analisis sistem adalah penguraian dari suatu sistem informasi yang utuh kedalam bagian - bagian komponennya dengan maksud untuk mengidentifikasikan dan mengevaluasi permasalahan, kesempatan, hambatan yang terjadi dan kebutuhan yang diharapkan sehingga dapat diusulkan perbaikan.[1]

Analisa sistem adalah teori sistem umum yang sebagai sebuah landasan konseptual yang mempunyai tujuan untuk memperbaiki berbagai fungsi didalam sistem yang sedang berjalan agar menjadi lebih efisien, mengubah sasaran sistem yang sedang berjalan, merancang/mennganti output yang sdang digunakan, untuk mencapai tujuan yang sama dengan seperangkat input yang lain (biasa jadi lebih sederhana dan lebih interatif) atau melakukan beberapa perbaikan serupa. [2]

\section{Sistem yang Diusulkan}

Sistem yang diusulkan adalah untuk memberikan gambaran secara umum kepada admin mengenai sistem penilaian kinerja guru yang baru, perancangan sistem secara umum sudah dapat mengenai komponen sistem penilaian kinerja guru yang akan didesain. persyaratan sistem yang dilakukan agar arah perancangan sistem dapat terarah pada sasaran, oleh karena itu sistem yang dirancang harus memenuhi batasan sistem dimana perancangan sistem ini merupakan kebutuhan fungsional dan persiapan untuk rancang bangun. pada tahap perancangan sistem penilaian kinerja guru dirancang dengan tujuan sebagai alat komunikasi antar pengguna dengan pembuat program guna mendapatkan sistem aplikasi yang sesuai dengan apa yang dibutuhkan.

a. Admin/user, melakukan login ke sistem.

b. Admin dapat mengelolah data guru seperti memasukkan data baru, melihat data yang sudah ada, merubah dan menghapus data yang sudah ada.

c. Admin dapat mengelola kriteria seperti memasukan data baru , mengubah dan menghapus data yang sudah ada.

d. Admin dapat memasukkan nilai bobot yang sudah di tentukan.

e. Admin dapa mengelola laporan hasil evaluasi.

f. Admin/user dapat melihat laporan hasil perangkingan dari penilaian kinerja guru.

g. Admin/user, melakukan logout dari sistem.

\section{PEMBAHASAN \\ Class Diagram}

Class Diagram adalah deskripsi kelompok objek-objek dengan property, operasi dan relasi yang sama. Class diagram sangat membantu dalam visualisasi suatu sistem.

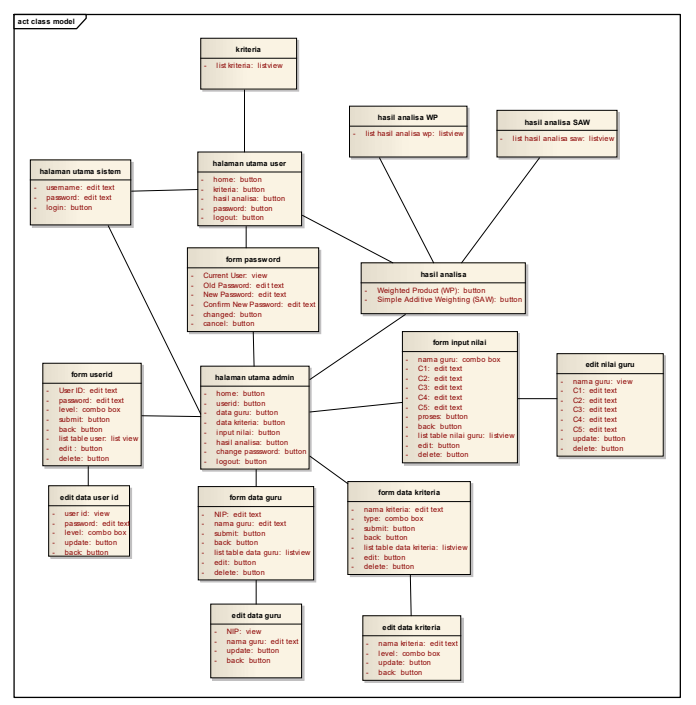

Gambar 3.1 Class Diagram

\section{Use case Diagram}

Pada sequence diagram menjelaskan aliran fungsionalitas dalam use case, berikut ini adalah gambaran sequence diagram-nya:

a. Sequence Diagram Login Admin 


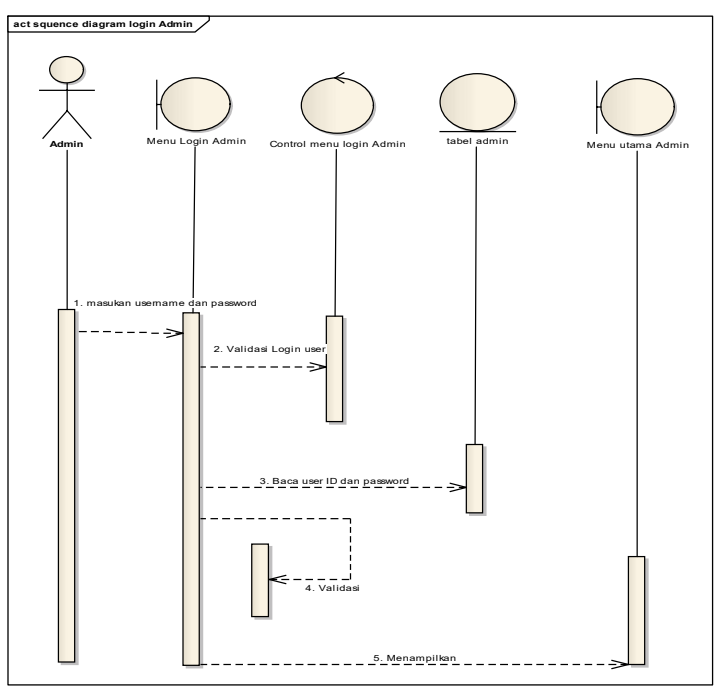

Gambar 3.2 Sequence Diagram Login Admin

b. Sequence Diagram Kriteria Penilaian

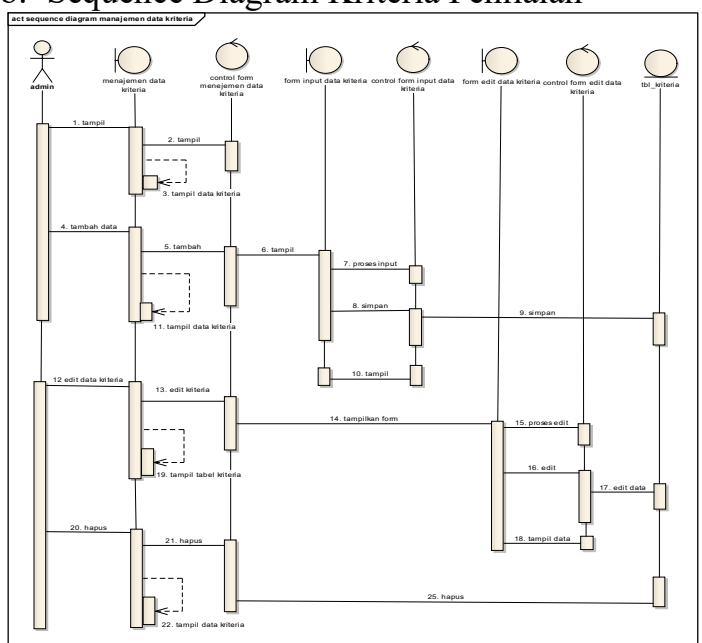

Gambar 3.3 Sequence Diagram Kriteria Penilaian

\section{Perancangan Antarmuka}

Dalam perancangan sistem penilaian kinerja guru ini, peneliti membuat layout yang terdiri dari beberapa form yaitu:

a. Form Login Admin

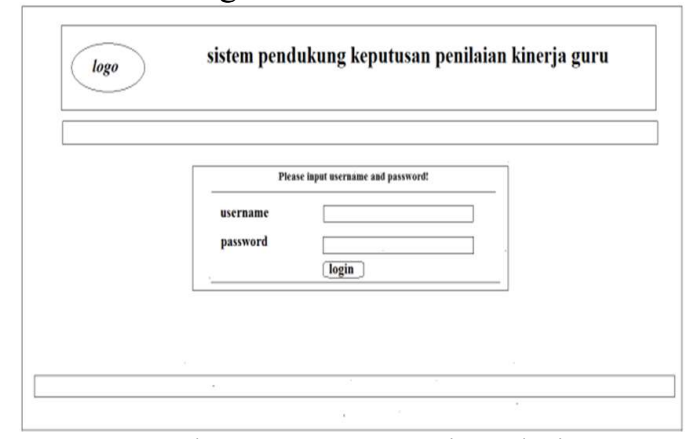

Gambar 3.4 Form Login Admin b. Form Home Admin

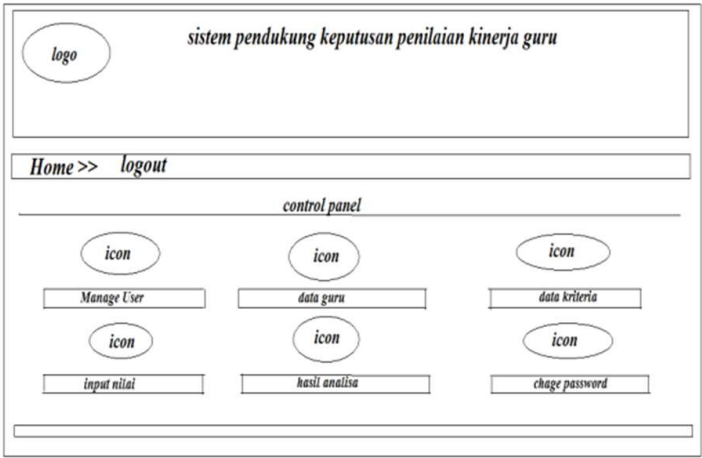

Gambar 3.5 Form Login Admin

c. Form Data Guru

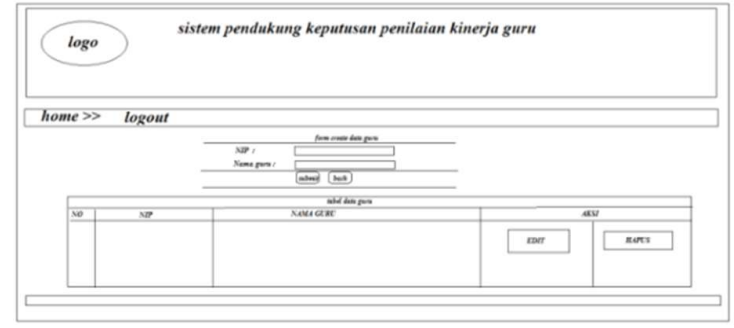

Gambar 3.6 Form Login Admin

d. Form Data Kriteria

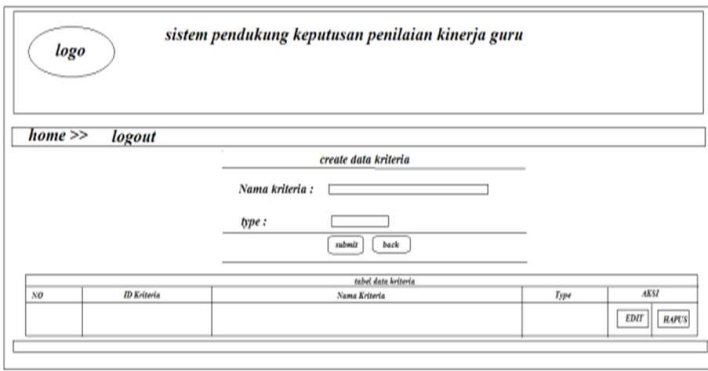

Gambar 3.7 Form Login Admin

\section{IMPLEMENTASI}

Implementasi merupakan salah satu unsur tahapan dari keseluruhan pembangunan sistem komputerisasi, dan unsur yang harus di pertimbangkan dalam pembangunan sistem komputerisasi yaitu masalah perangkat lunak yang digunkan haruslah sesuai dengan masalah yang akan diselesaikan, disamping masalah perangkat keras (hardware) itu sendiri.

\section{Implementasi Halaman Utama}

Form halaman utama merupakan sentral dari semua halaman page, page ini berisi menumenu utama yang dapat mengakses dan menjadi penghubung antara pengguna dan sistem. berikut ini implemntasi struktur menu pada halaman utama sistem penilaian kinerja guru. 


\section{Implementasi Antarmuka}

Adapun user interface yang sudah dibuat adalah sebagai berikut:

a. Halaman utama admin

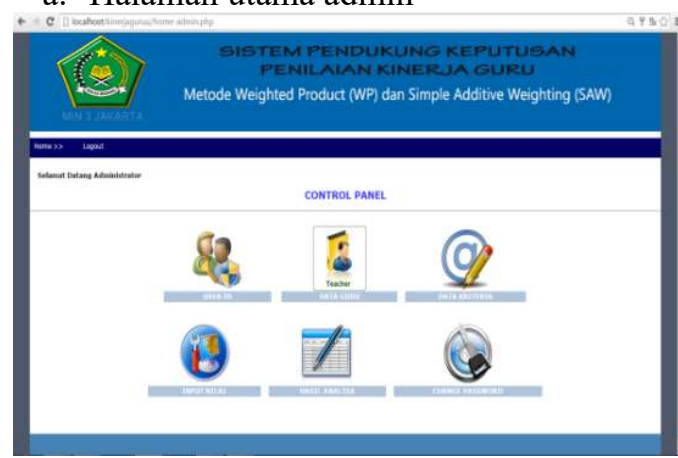

Gambar 4.1 Menu Admin

b. Tampilan menu user ID

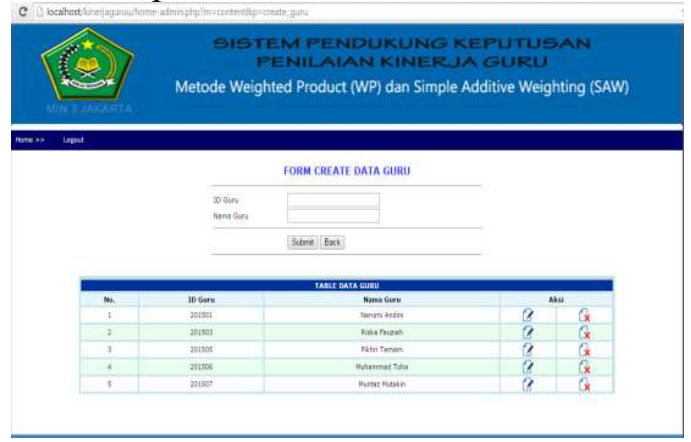

Gambar 4.2 Tampilan menu user ID

c. Tampilan menu data kriteria

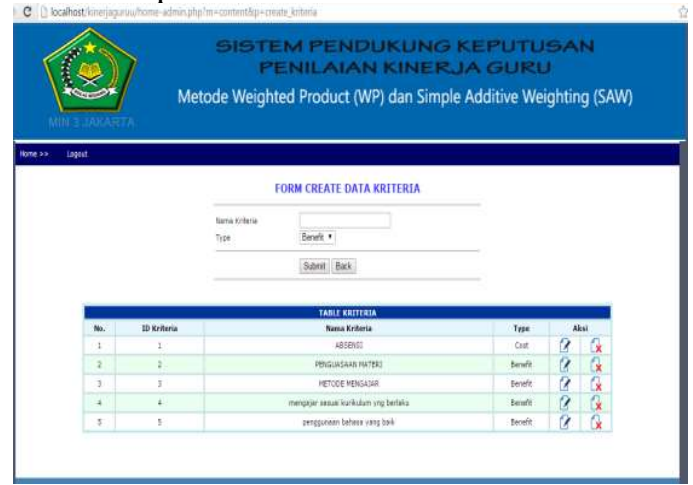

Gambar 4.3 Tampialan menu data kriteria

d. Tampilan hasil analisa SAW

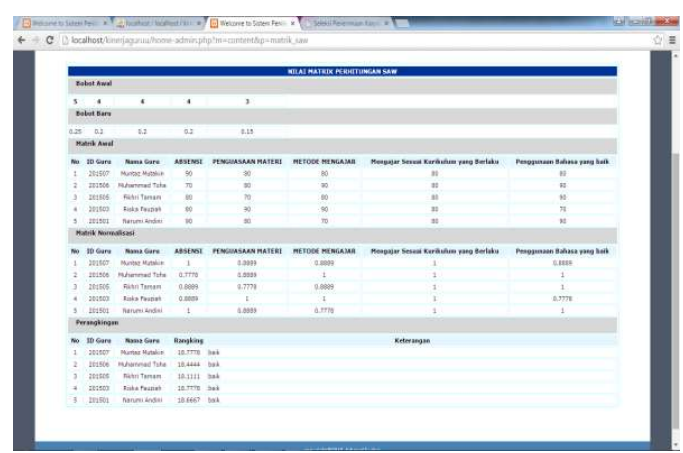

Gambar 4.4 Tampilan hasil analisa SAW

\section{e. Tampilan hasil analisa WP}

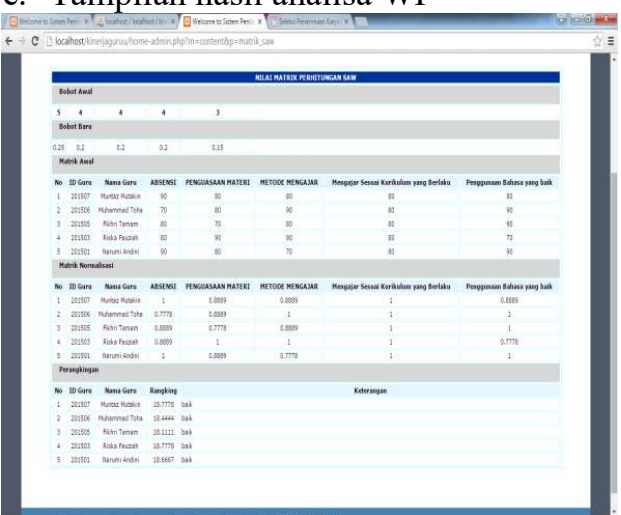

Gambar 4.5 Tampilan hasila analisa WP

\section{KESIMPULAN}

metode Weighted Product (WP) lebih baik dari metode Simple Additive Weighting (SAW) dalam beberapa kasus. dan berdasarkan bab analis dan pembahasan "implementasi perbandingan metode Weighted Product (WP) dan Simple Additive Weighting (SAW) penilaian kinerja guru di MIN 3 Jakarta, maka dapat ditarik kesimpulan:

a. Dengan adanya database sistem pendukung keputusan penilaian kinerja guru di MIN 3 Jakarta yang dihasilkan dapat mempercepat proses penilaian kinerja guru.

b. Sistem yang di bangun dapat menbantu kepala sekolah dalam proses perangkingan yang akurat untuk mengevaluasi kinerja guru.

\section{DAFTAR PUSTAKA}

[1] Kadir, Abdul. (1999). Konsep dan Tuntunan Praktis Basis Data, Yogyakarta, Andi.

[2] Rainer \& Cegielski. (2007), "Introduction to Information Technology", John Wiley \& Sons, Inc. USA

[3] O’Brien James A, (2006), "Pengantar Sistem Informasi Perspektif Bisnis dan Manajerial," Salemba Empat. Jakarta. 
[4] Dawson, C. W. (2009). Project in Computing and Information System a Student Guide 2nd Edition. Addison-Wesley.

[5] Gerdon. (2011). Sistem pendukung keputusan penilaian kinerja guru menggunakan metode Weighted Product

[6] Juliyanti, Irawan, M. I., \& I. M. (2011). Pemilihan Guru Berprestasi Menggunakan Metode AHP dan TOPSIS.

[7] Khoriyah, U. A. (2013). Penerapan Analytical Hierarchy Process (AHP) dalam pendukung keputusan penilaian kinerja Guru

[8] Roger S. Pressman, P. (2001). Software Engineering: A Practitioner's Approach. In R. S. Pressman, Software Engineering. New York: Thomas Casson.

[9] Wibowo, H. (2010). MADM-TOOL : APLIKASI UJI SENSITIVITAS UNTUK MODEL MADM MENGGUNAKAN METODE SAW DAN TOPSIS. Seminar Nasional Aplikasi Teknologi Informasi 2010 (SNATI 2010).

[10] Sugiarti, Y. (2013). Analisis \& Perancangan UML (Unified Modeling Language) Generated VB.6. Yogyakarta: Graha Ilmu. 